Original Article

Received/Accepted

Dates

29.05.2021/25.06.2021

DOI

10.52096/jsrbs.6.1.7.13.19
Journal of Social Research and Behavioral Sciences

Sosyal Araştırmalar ve Davranış Bilimleri Dergisi

ISSN:2149-178X

Volume: 7 Issue: 13 Year: 2021

\title{
Optik Disk Hipoplazili Bir Çocukta Kanada Okupasyonel Perfomans Modeli’ne Göre Ergoterapi Müdahalesinin Etkinliğinin İncelenmesi: Olgu Çalışması
}

Uzm. Erg. Gözde ÖNAL Nevşehir Hacı Bektaşi Veli Üniversitesi

Terapi ve Rehabilitasyon Bölümü gozdeonal0@gmail.com ORCID: 0000-0002-6656-965X Uzm. Erg. Güleser GÜNEY YILMAZ Kütahya Sağlık Bilimleri Üniversitesi Terapi ve Rehabilitasyon Bölümü guleser.guney.gg@gmail.com ORCID: 0000-0003-1781-9381

\section{Özet}

Optik disk hipoplazisi (ODH) tek ya da çift taraflı gelişebilen azalmış retina sinir lifi sayısı ve normal gelişim gösteren retinal doku ile birlikte olan progresif olmayan bir tablodur. ODH'li bireylerde görme azalması, görsel alan değişiklikleri ve renkli görmede defektler görülebilmektedir. Çalışmaya sağ gözünde ODH bulunan, 3 yaşında erkek bir pediatrik olgu dahil edilmiştir. Olgunun kişisel, çevresel ve okupasyonel faktörlerinin bütüncül değerlendirmesi için Kanada Okupasyonel Performans Modeli (CMOP), müdahale uygulaması için ise Görsel Algılama Referans Çerçevesi kullanılmıştır. CMOP kapsamında problem alanları, çatal kaşık tutmada zorlanma bu nedenle yemekleri dökerek yeme, kağıt üzerindeki küçük resimleri ayırt edememe renk ve şekil-zemin algısında zayıflık ve kaba motor becerilerde zayıflık (tek ayak üstünde durma, yerinde zıplama) olarak belirlenmiştir. 8 haftalık müdahale planında kısa dönem hedefler, görsel ayırt etme (tanıma, eşleştirme, sınıflandırma) becerilerinin gelişmesi, renk algısı ve şekil algısının gelişmesi, yardımcı araç-gereç yardımı ile (kalınlaştırılmış çatal kaşık) yemek yemede bağımsızlık seviyesini artırma; uzun dönem hedefler, şekil zemin algısının gelişmesi, görsel dikkatin gelişmesi ve görsel motor integrasyonun gelişmesi olarak belirlenmiştir. Hedeflere yönelik oluşturulan ergoterapi müdahale programı ile olgunun kalınlaştırılmış çatal-kaşık yardımı ile bağımsız yemek yemesi, basit şekillerde, büyük 
parçalı ve parlak renkli yap-boz parçalarını birleştirebilir hale gelmesi, tek ayak üzerinde durabilme süresinin artması ve iki ayak üzerinde zıplayabilmesi sağlanmıştır. ODH gibi görme alanını etkileyen tanılarda görsel algı çalışmalarını içeren daha çok sayıda ve kanıt temelli ergoterapi çalışmasına ihtiyaç duyulmaktadır.

Anahtar Kelimeler: optik disk hipoplazisi, holistik bakış, görsel algılama, ergoterapi

\title{
An Investigation of the Efficacy of Occupational Therapy Intervention According to the Canadian Model of Occupational Performance in a Child with Optic Disc Hypoplasia: A Case Study
}

\begin{abstract}
Optic disc hypoplasia (ODH) is a non-progressive condition that can develop unilaterally or bilaterally, with decreased retinal nerve fiber count and normally developing retinal tissue. Decreased vision, visual field changes and defects in color vision mau be seen in individuals with ODH. A 3-year-old male pediatric case with ODH in the right eye was included in the study. The Canadian Model of Occupational Performance (CMOP) was used for the holistic evaluation of the individual, environmental and ocupational factors of the case, and the Visual Perception Reference Frame was used for the intervention application. The problem areas within the scope of CMOP were determined as difficulty in holding cutlery and therefore eating by spilling food, inability to distinguish small pictures on paper, weakness in perception of color and figure-ground, and weakness in gross motor skills (standing on one leg, jumping in place). The short-term goals in the 8-week intervention plan, development of visual discrimination (recognition, matching, classification) skills, development of color perception and figure perception, increasing the level of independence in eating with the help of auxiliary equipment (thickened cutlery); the long-term goals were determined as the development of figure-ground perception, the development of visual attention and the development of visual motor integration. With the target spesicif occupational therapy intervention program, the case was able to eat independently with the help of thickened cutlery, to be able to combine simple figures, large pieces and brightly colored puzzle pieces, to increase the time to stand on one leg, and to jump on two legs. There is a need for more evidence-based occupational therapy studies including visual perception studies in diagnoses affecting the visual field such as ODH.
\end{abstract}

Keywords: optic disc hypoplasia, holistic view, visual perception, occupational therapy 


\section{Giriş}

Optik disk hipoplazisi (ODH), retina gangliyon hücrelerinin ve optik sinir aksonlarının konjenital kusurudur ve klinik olarak bir veya iki gözde ilerleyici olmayan görme bozukluğu ve görme alanı kusurları ile karakterizedir (Ohguro vd., 2010: 547).

ODH, çocukluk çağında önemli görme bozukluğunun yaygın bir nedenidir (Hatton vd., 2007: 351). ODH öncelikle bir veya iki gözde anormal derecede küçük optik disk ile karakterizedir. Optik sinir solukluğu, çift halka işareti veya kıvrımlı retinal damarlar değişken olarak mevcuttur. Diğer yaygın bulgular arasında septo-optik displazi, kortikal malformasyonlar ve gelişimsel gecikme yer almaktadır (Fink vd., 2012: 418; Walton, Robb, 1970: 572). ODH'nin nedeni bilinmemektedir, ancak çoklu risk faktörleri veya retina ganglion hücre gelişiminin düzenlenmesinde genetik kusurlar öne sürülmektedir (Kelly vd., 2016: 159). Gebelik sırasında optik sinirin yetersiz gelişmesi ile oluştuğu bilinmektedir. Nistagmus ve iki taraflı ciddi görme kaybı olan çocuklarda, bu durum beyin ve hormonal anormalliklerle ilişkilidir; bu anormallikler, görme kaybının hafif veya tek taraflı olduğu durumlarda daha az görülmektedir (Bahar vd., 2003: $15)$.

ODH, şu anda görme engelliler için erken müdahale programlarına katılan çocukların en yaygın üçüncü göz rahatsızlığıdır (Hatton, 2001: 418). Özel eğitim programları bu tanıda bir artış gördükçe, eğitimciler ve sağlık profesyonelleri bu popülasyonda tutarlı olan ortak özellikleri, davranışları ve öğrenme modellerini gözlemlemeye başlamaktadır. Özellikle ciddi görme kaybı olan çocukların bilgi işlemlemede orta/şiddetli gecikmeler, aşırı dokunsal ve işitsel savunmacılık, görev geçişlerinde zorluk, rutine sıkı bağlılık, ritimlere ve müziğe yoğun ilgi, kısıtlı yiyecek tercihleri ve dokulu yiyeceklere karşı isteksizlikle ilgili yeme sorunları, sosyal etkileşim ve katılımdan kaçınma, dikkat dağınıklığı, hafif hipotoni (düşük kas tonusu), motor fonksiyonlarda gelişimsel gecikmeler, çevrelerini keşfetmede eksiklik, atipik dil gelişimi ve sözlü etkileşimlerde eksiklik gibi sekonder problemlerin bir kısmını veya tamamını sıklıkla sergiledikleri bilinmektedir (Bahar vd., 2003: 15). ODH'li çocuklarla çalışan profesyoneller, uygun müdahaleleri geliştirebilmek ve sağlayabilmek için bu durumla ilişkili özel ihtiyaçların farkında olmalıdır. ODH'ye sahip bir çocuk, çevresel uyarlamalar ve rehabilitasyon hedefleri yerinde olduğunda optimal başarıya ulaşabilmektedir (Bahar vd., 2003: 15). 
Bu çalışmanın amacı, ODH'ye sahip bir çocuğun bütüncül olarak değerlendirilerek, uygun ergoterapi programı ile desteklenmesini sağlamak ve bağımsızlığını artırmaktır.

\section{Yöntem}

Çalışmaya sağ gözünde ODH bulunan, 3 yaşında erkek bir pediatrik olgu dahil edilmiştir. Olgunun bütüncül değerlendirmesi için Kanada Okupasyonel Performans Modeli kullanılmıştır. Bütüncül değerlendirme kapsamında; Dunn Duyu Profili, Motor Beceriden Bağımsız Görsel Algı Testi-3 (MVPT 3) ve Çocuklar İçin Fonksiyonel Bağımsızlık Ölçümü (WeeFIM) kullanılmıştır.

Müdahale programı için Görsel Algılama Referans Çerçevesi kullanılmış ve 8 hafta, haftada 40 dakika süren 1 seans planlanarak çocuk ergoterapi programına alınmıştır.

\section{Kanada Okupasyonel Performans Modeli (COPM)}

Kanada Okupasyonel Performans Modeli, ergoterapi felsefesi ve kişi merkezli rehabilitasyon yaklaşımını temel alarak, değerlendirme ve müdahaleye rehberlik etmesi için geliştirilmiştir. $\mathrm{Bu}$ model, okupasyonel performans alanları olan; kendine bakım, üretkenlik ve serbest zaman aktiviteleri ile bu alanlardaki rolleri yürütmek için gerekli performans bileşenleriyle ilgilenir. Performans bileşenleri, fiziksel, bilişsel ve ruhsal durum alt bileşenlerine ayrılır. Model ayrıca birey ile bireyin etkileşimde olduğu fiziksel, kültürel, sosyal ve kurumsal çevresi arasındaki aktif ilişkiyi de göstermektedir (Torpil, 2017).

\section{Dunn Duyu Profili}

$\mathrm{Bu}$ test, engel grubu ve etkilenim derecesi ayırt edilmeden 3 ile 10 yaş arası tüm çocuklar için kullanılabilmektedir. Çocuğun günlük yaşamında en çok iletişimde olduğu kişi eşliğinde ergoterapist tarafından doldurulur. Her madde Likert skalasına göre 1-5 arasında puanlanır. Duyu profili; duyusal işlem, modülasyon, davranışsal- duygusal cevaplar olarak üç bölümden ve 14 parametreden oluşur. Her parametre kesin farkl11ık, muhtemel farklılık, tipik performans şeklinde tanımlanır. Kesin farklılık puan aralığından tipik performans puan aralığına doğru geçiş duyusal modülasyon, duyusal işlemleme ve davranışsal-duygusal cevaplarda gelişimi tanımlar (Huri, Gündüz, 2016: 137). 


\section{Motor Beceriden Bă̆ımsız Görsel Algı Testi-3}

Motor Beceriden Bağımsız Görsel Algı Testi-3 (MVPT-3) görsel ayrım (1-8), şekil oluşturma (913), görsel hafıza-I (14-21), görsel yakınlık-I (22- 34), görsel ayırt etme (35-45), mekânda konum (46-50), şekil zemin (51-55), görsel yakınlık II (56-60) ve görsel hafiza II (61-65) olmak üzere toplam 9 ana başlıktan ve 65 şekilden oluşmaktadır. Dört-doksan beş yaş arasındaki bireylere bireysel olarak uygulanabilen test, 65 maddeden oluşmaktadır. Uygulama her bir çocuk için yaklaşık 15-20 dakika sürmektedir (Metin, Neriman, 2012: 57).

\section{Çocuklar İçin Fonksiyonel Bağımsızlık Ölçümü̈ (WeeFIM)}

WeeFIM, engel düzeyi fark etmeksizin 6 ay ile 7 yaş arasındaki çocuklarda fonksiyonel bağımsızlığın değerlendirilmesinde kullanılmaktadır (Wong vd., 2005: 613). 6 alt bölüme (kendine bakım, sfinkter kontrolü, transfer, hareket, iletişim, sosyal iletişim) ayrılmış 18 maddeden oluşmaktadır. Ebeveyn tarafından doldurulan ölçekte çocuk, her bir alt maddeden 1 (tam yardım)7 (tamamen bağımsız) arası puan alır (Ottenbacher vd., 2000: 1317). Ölçekten alınabilecek puanlar 18 ile 126 arasında değişmektedir. Yüksek puan, günlük yaşamda fonksiyonel bağımsızlığın yüksek olduğunu göstermektedir (Wong vd., 2002: 36).

\section{Görsel Algılama Referans Çerçevesi}

$\mathrm{Bu}$ referans çerçevesi, ergoterapistler tarafından görsel algılama problemi olan bireylerde müdahale planı geliştirme ve uygulamada rehber olarak kullanılmaktadır (Case-Smith vd., 1996). Bu referans çerçevesinin teorik temelinde 5 temel varsayım vardır: (1) Görsel algılama gelişimsel bir süreçtir. (2) Görsel algılama süreci öğrenilir ve gelişim, deneyim, pratik ve çevreden alınan uyarılar ile artar. (3) Çocuklar yetişkinleri veya diğer çocukları gözlemleyerek veya onlar ile etkileşim halinde olarak öğrenebilirler. (4) Öğrenme her zaman gelişimsel sıralamayı takip etmez. Bir alandaki defisit başka bir alandaki problem veya defisit ile ilgili tahmin vermez. (5) Görsel algılama ile ilgili zorluk okuma ve yazma becerilerinin gelişimini içeren günlük yaşam aktivitelerini etkileyebilir. 


\section{Bulgular}

\section{Duyusal İşlemleme Becerileri ile ilgili Bulgular}

Dunn Duyu Profili sonuçlarına göre, olgunun müdahale öncesi ve müdahale sonrası tüm duyusal işlemleme süreçlerinde iyileşmeler görülmüştür. Olgunun işitsel işlemleme ve görsel işlemleme süreçleri müdahale öncesinde akranlarına göre tipik farklılık gösterirken, müdahale sonrası işlemleme seviyesine akranlarının seviyesine yaklaşmıştır. Ergoterapi müdahalesi sonrasında olgunun duyusal işlemleme süreçlerinde meydana gelen değişimler Tablo 1'de görülmektedir.

Tablo 1. Olgunun duyusal işlemleme süreçlerinde meydana gelen değişim.

\begin{tabular}{|c|c|c|c|c|}
\hline Duyusal işlem & \multicolumn{2}{|c|}{ Müdahale öncesi } & \multicolumn{2}{|c|}{ Müdahale sonrası } \\
\hline İşitsel işlem & $25 / 40$ & Kesin farklılık & $28 / 40$ & Olası farklılık \\
\hline Görsel işlem & $24 / 45$ & Kesin farklilık & $20 / 45$ & Olası farkl11ık \\
\hline Vestibular işlem & $53 / 55$ & Tipik performans & $54 / 55$ & Tipik performans \\
\hline Dokunma işlemi & $68 / 90$ & Olası farklılık & $75 / 90$ & Tipik performans \\
\hline Çoklu duyusal işlem & $32 / 35$ & Tipik performans & $34 / 35$ & Tipik performans \\
\hline Oral duyusal işlem & $36 / 90$ & Olası farklılık & $41 / 90$ & Olası farklılık \\
\hline $\begin{array}{l}\text { Enduransla/tonusla ilgili } \\
\text { duyusal ișlem }\end{array}$ & $45 / 45$ & Tipik performans & $45 / 45$ & Tipik performans \\
\hline $\begin{array}{l}\text { Hareket ve vücut } \\
\text { pozisyonu ile ilgili } \\
\text { düzenlemeler }\end{array}$ & $36 / 45$ & Olası farklılık & $41 / 45$ & Tipik performans \\
\hline $\begin{array}{l}\text { Aktivite seyiyesini } \\
\text { etkileyen hareket }\end{array}$ & $25 / 35$ & Tipik performans & $30 / 35$ & Tipik performans \\
\hline
\end{tabular}




\begin{tabular}{l|cccc}
$\begin{array}{l}\text { Duygusal cevapları ve } \\
\text { aktivite seviyesini } \\
\text { etkileyen görsel uyarıların } \\
\text { düzenlenmesi }\end{array}$ & $15 / 20$ & Tipik performans & $17 / 20$ & Tipik performans \\
$\begin{array}{l}\text { Duygusal ve sosyal } \\
\text { cevaplar }\end{array}$ & $69 / 85$ & Tipik performans & $72 / 85$ & Tipik performans \\
$\begin{array}{l}\text { Duyusal işlemin } \\
\text { davranışsal sonuçları }\end{array}$ & & & & \\
& & & & \\
Tepki verme eşiğini & $14 / 15$ & Tipik performans & $15 / 15$ & Tipik performans \\
tanımlayan maddeler & & & & \\
\hline
\end{tabular}

\section{Görsel Algllama ile ilgili Bulgular}

Motor Beceriden Bağımsız Görsel Algı Testi-3 (MVPT-3) sonuçlarına göre, olgunun görsel hafıza, görsel tamamlama, görsel ayrım, görsel uzaysal ilişki ve şekil-zemin algısı becerilerinde ergoterapi müdahalesi sonrasında iyileşmeler olduğu görülmüştür (Tablo 2).

Tablo 2. Olgunun görsel algılama becerilerinde meydana gelen değişim.

\begin{tabular}{lcc}
\hline \multicolumn{1}{c}{ MVPT-3 parametreleri } & Müdahale öncesi & Müdahale sonrası \\
\hline Görsel hafıza I & $5 / 8$ & $6 / 8$ \\
Görsel tamamlama I & $5 / 13$ & $8 / 13$ \\
Görsel ayrım & $4 / 11$ & $6 / 11$ \\
Görsel uzaysal ilişki & $1 / 5$ & $3 / 5$ \\
Şekil-zemin algısı & $2 / 5$ & $3 / 5$ \\
Görsel tamamlama II & $2 / 5$ & $3 / 5$ \\
Görsel hafıza II & $1 / 5$ & $2 / 5$ \\
\hline
\end{tabular}

MVPT-3: Motor Beceriden Bağımsız Görsel Algı Testi-3 


\section{Günlük Yaşam Aktiviteleri ile ilgili Bulgular}

Çocuklar İçin Fonksiyonel Bağımsızlık Ölçümü (WeeFIM) sonuçlarına göre, ergoterapi müdahalesi sonrası olgunun kendine bakım, bir yerden bir yere transger, hareket etme, iletişim ve sosyal becerilerinde iyileşmeler olduğu görülmüştür (Tablo 3).

Tablo 3. Olgunun günlük yaşam aktivitelerinde meydana gelen değişim.

\begin{tabular}{lcc}
\hline WeeFIM parametreleri & Müdahale öncesi(-/126) & Müdahale sonrası (-/126) \\
\hline Kendine Bakım & 10 & 18 \\
Sfinkter kontrolü & 2 & 2 \\
Transferler & 17 & 19 \\
Hareket & 10 & 13 \\
İletişim & 12 & 13 \\
Sosyal durum & 18 & 20 \\
Toplam & 69 & 85 \\
\hline
\end{tabular}

WeeFIM: Çocuklar İçin Fonksiyonel Bağımsızlık Ölçümü

\section{Müdahale hedefleri}

Olgunun ilk değerlendirme sonuçlarına göre belirlenen kısa dönem ve uzun dönem hedefler Tablo 4'te görülmektedir.

Tablo 4. Olgu için belirlenene kısa ve uzun dönem müdahale hedefleri.

\begin{tabular}{|l|l|}
\hline \multicolumn{1}{|c|}{ Kısa dönem hedefler } & \multicolumn{1}{c|}{ Uzun dönem hedefler } \\
\hline $\begin{array}{l}\text { Görsel ayrım (tanıma, eşleştirme, } \\
\text { sınıflandırma) becerilerinin gelişmesi }\end{array}$ & Şekil-zemin algılamasının gelişmesi \\
\hline Renk algısı ve şekil algısının gelişmesi & Görsel dikkatin gelişmesi \\
\hline $\begin{array}{l}\text { Yardımcı teknoloji yardımı ile } \\
\text { (kalınlaştırılmış çatal-kaşık) yemek yemede } \\
\text { bağımsızlık seviyesini artırma }\end{array}$ & Görsel-motor integrasyonun gelişmesi \\
\hline
\end{tabular}




\section{Müdahale örnekleri}

- Ailenin isteği üzerine yemek yeme aktivitesi çalışıldı. Önce oyuncak mutfak eşyaları ile oyuncak bebeğe yemek yedirme çalışıldı.

- Daha sonra makarna yeme aktivitesi için kalınlaştırılmış çatal ve normal kalınlıktaki çatal ayrı ayrı denendi ve çocuk gözlemlendi. Kalınlaştırılmış çatalda çocuğun kavraması daha düzgündü bu nedenle aileye kalınlaştırılmış çatal ve kaşık tavsiye edildi.

- Renkli küpleri aynı renkte kartlara yerleştirme yapılarak görsel dikkat, renk algısı, eşleştirme-sınıflandırma çalışıldı.

- Görsel alg1 (renk algısı, hareket algısı) için renkli çubuklar delikleri olan kutuya atıldı. Kutu çocuğun sol tarafina, orta hattına ve sağ tarafına yerleştirilerek aktivite tamamlandı.

- Müzik eşliğinde zıplama, yere dökülen topları farklı mesafelerden getirerek sepete koyma, tek ayak üzerinde durma, top oynama aktiviteleri ile kaba motor beceriler ve çoklu duyusal işlemleme becerileri çalışldı.

\section{Aileye öneriler}

- Kalınlaştırılmış çatal-kaşık önerildi. Saplarının çocuğun göreceği parlak renklerde tercih edilmesi tavsiye edildi.

- Büyük parçalı ve parlak renklerde yap-bozlar önerildi.

- Bir obje uzatırken sağ taraftan yaklaşılması ve odasında eşyaların çoğunlukla sağ tarafa yerleştirilmesi tavsiye edildi.

\section{Tartışma}

Çalışmamızda; ODH'ye sahip bir çocuğa uygulanan kişi, çevre ve okupasyonları bütüncül olarak ele alan ergoterapi müdahalesinin etkisi incelenmiştir. 8 hafta sonunda çocuğun görsel algılama becerilerinde, bağımsız yemek yeme ve duyusal işlemleme becerilerinde becerilerinde pozitif yönde anlamlı gelişmeler gösterdiği tespit edilmiştir.

Literatür incelendiğinde ODH'li çocuklarda duyusal farklılıklar olabildiği görülmektedir (Bahar vd., 2003: 15). Günlük yaşam aktivitelerine katılımı etkileyen en önemli faktörlerden birisi de duyusal işlemleme becerileridir ve duyusal işlemleme bozuklukları bireylerin günlük yaşam 
aktivitelerine katılımını etkilemektedir. Ergoterapistler öz-düzenleme, dikkat ve davranış kontrolü için özel duyusal modaliteleri kullanmaktadır (Kayıhan, Kars, 2019: 37). Duyu bütünleme yaklaşımlarının otizm spektrum bozukluğu, dikkat eksikliği ve hiperaktivite bozukluğu, disleksi, işitme kaybı, prematüre bebekler, serebral palsi, Williams sendromu, şizofreni gibi farklı tanı ve yaş gruplarında olumlu etkilerinin olduğu bilinmekle birlikte; bu çalışma, praksis, nistagmus ve modülasyon problemlerini azaltmaya yönelik uygulanan duyu temelli ergoterapi müdahalelerinin ODH'li çocuğun duyusal işlemleme becerilerini geliştirdiğini göstermiştir.

Görsel algılama becerisi, görsel uyaranları tanıma, ayırt etme ve daha önceki deneyimlerle ilişkili olarak yorumlama yeteneği anlamına gelmektedir ve ODH'ye sahip bireylerin görsel algılama becerilerinde zayıflık olduğu literatürde açıkça belirtilmektedir (Metin, Neriman, 2012: 57; Petersen, Walton, 1977: 254; Teär Fahnehjelm vd., 2014: 563). Ergoterapistler, tanı fark etmeksizin bireylerin görsel algılama becerilerini geliştirmeye yönelik çeşitli stratejiler kullanmaktadır (Dankert vd., 2003: 542; Vlok vd., 2011: 25). Bu çalışmada, duyu temelli çalışmalar, aktivitelerde adaptif araç gereç kullanımı ve bireyin yaşadığı alanla ilgili düzenleme önerileri ile ODH’ye sahip olgunun görsel algılama becerilerinin geliştiği görülmüştür.

Görsel algılama becerilerindeki eksiklikler genellikle azalmış fonksiyonel yetenekleri beraberinde getirmektedir. Bu eksiklikleri olan bir çocuk, el yazısı, okuma, yemek yeme, giyinme ve diğer motor beceri gerektiren aktivitelerde sorunlar sergileyebilmektedir (Parush vd., 1998: 291). Araştırmada yer alan ODH'li çocuk, bağımsız yemek yeme ve giyinme aktivitelerinde problemler sergiyelen bir olgu idi. Ergoterapi müdahalelerinde, özellikle görsel defektlere sahip bireyler için yaygın olarak kullanılan Görsel Algılama Referans Çerçevesi, görsel algılama süreci öğrenilen bir süreç olduğunu, gelişim, deneyim, pratik ve çevreden alınan uyarılar ile artabildiğini savunmaktadır ve bu çerçeveye göre görsel algılama problemleri günlük yaşam aktivitelerini etkileyebilmektedir. Bu prensiplerden faydalanarak, çalışma kapsamında; çocuğun görsel algılama becerilerini geliştirerek günlük yaşam aktivitelerinde bağımsızlığını artırmak için seanslarda tekrarlı-dereceli bir şekilde farklı duyu uyaranları ve adaptif ekipman desteği ile ailenin özellikle üzerinde durduğu yemek yeme aktivitesi çalışıldı. Ergoterapi müdahalesi sonrasında çocuğun kalınlaştırılmış çatal-kaşık ile bağımsız bir şekilde yemek yemesi sağlandı. Çalışma, ODH'ye sahip bir çocuğun görsel algılama becerileri desteklendiğinde günlük yaşam aktivitelerinde de bağımsızlığının arttı̆̆ını gösterdi. 
Ergoterapistler tarafından gerçekleştirilen az gören rehabilitasyonunun amacı, bireylerin bağımsızlığını desteklemek ve tam sosyal katılımı gerçekleştirmektir (Duquette vd., 2019: 457). Bu çalışma, ODH'ye sahip bir çocuğun, kişi, çevre ve okupasyonları içeren bütüncül ergoterapi programı ile desteklendiğinde görsel algılama becerileri, duyusal işlemleme becerileri ve günlük yaşam aktivitelerindeki bağımsızlık seviyesinin geliştiğini göstermiştir. Kanıt seviyesini artırmak ve ODH'li çocuklarda bütüncül rehabilitasyon programlarının yaygınlaşmasını desteklemek için geniş katılımcı grupları ile randomize kontrollü çalışmaların yapılması önerilmektedir.

\section{Kaynaklar}

Bahar C, Brody J, McCann ME, Mendiola R, Slott G. 2003. A multidisciplinary approach to educating preschool children with optic nerve hypoplasia and septo-optic nerve dysplasia. Re:view. p. $15+$.

Case-Smith J, Allen AS, Pratt PN. 1996. Occupational therapy for children. Mosby St. Louis.

Dankert HL, Davies PL, Gavin WJ. 2003. Occupational therapy effects on visual-motor skills in preschool children. American Journal of Occupational Therapy. 57(5):542-549.

Duquette J, Loiselle J, Fréchette C, Déry L, Senécal M-J. 2019. Occupational performance in the basic and instrumental daily activities of persons with low vision who received rehabilitation services. British Journal of Occupational Therapy. 82(8):457-465.

Fink C, Vedin AM, Garcia-Filion P, Ma NS, Geffner ME, Borchert M. 2012. Newborn thyroidstimulating hormone in children with optic nerve hypoplasia: Associations with hypothyroidism and vision. Journal of American Association for Pediatric Ophthalmology and Strabismus. 16(5):418-423.

Hatton DD. 2001. Model registry of early childhood visual impairment: First-year results. Journal of Visual Impairment \& Blindness. 95(7):418-433.

Hatton DD, Schwietz E, Boyer B, Rychwalski P. 2007. Babies count: The national registry for children with visual impairments, birth to 3 years. Journal of American Association for Pediatric Ophthalmology and Strabismus. 11(4):351-355. 
Huri M, Gündüz F. 2016. Üstün yetenekli çocuklarda duyu temelli ergoterapi grup müdahalesinin duyu modülasyonu, postural praksis ve bilateral motor koordinasyon becerileri üzerindeki etkisinin incelenmesi: Pilot çalışma. Ergoterapi ve Rehabilitasyon Dergisi. 4(3):137-144.

Kayıhan H, Kars S. Katılım temelli duyu bütünleme. Kayıhan H, editör. Toplumsal Katılım ve Ergoterapi. 1. Bask1. Ankara: Türkiye Klinikleri; 2019. p.37-42.

Kelly JP, Phillips JO, Weiss AH. 2016. Vep analysis methods in children with optic nerve hypoplasia: Relationship to visual acuity and optic disc diameter. Documenta Ophthalmologica. 133(3):159-169.

Metin Ş, Neriman A. 2012. Motor beceriden bağımsız görsel algı testi-3: Geçerlik güvenirlik çalışması. Çankırı Karatekin Üniversitesi Sosyal Bilimler Enstitüsü Dergisi. 4(2):57-72.

Ohguro H, Ohguro I, Tsuruta M, Katai M, Tanaka S. 2010. Clinical distinction between nasal optic disc hypoplasia (noh) and glaucoma with noh-like temporal visual field defects. Clinical Ophthalmology (Auckland, NZ). 4:547.

Ottenbacher KJ, Msall ME, Lyon N, Duffy LC, Ziviani J, Granger CV, Braun S, Feidler RC. 2000. The weefim instrument: Its utility in detecting change in children with developmental disabilities. Archives of physical medicine and rehabilitation. 81(10):1317-1326.

Parush S, Yochman A, Cohen D, Gershon E. 1998. Relation of visual perception and visual-motor integration for clumsy children. Perceptual and motor skills. 86(1):291-295.

Petersen RA, Walton DS. 1977. Optic nerve hypoplasia with good visual acuity and visual field defects: A study of children of diabetic mothers. Archives of Ophthalmology. 95(2):254258.

Teär Fahnehjelm K, Dahl S, Martin L, Ek U. 2014. Optic nerve hypoplasia in children and adolescents; prevalence, ocular characteristics and behavioural problems. Acta ophthalmologica. 92(6):563-570.

Torpil B. 2017. Multipl skleroz'lu bireylerde kanada aktivite performans ölçümü’nün türkçe kültürel adaptasyonu, geçerlilik ve güvenilirliği.

Vlok ED, Smit NE, Bester J. 2011. A developmental approach: A framework for the development of an integrated visual perception programme. South African Journal of Occupational Therapy. 41(3):25-33.

Walton DS, Robb RM. 1970. Optic nerve hypoplasia: A report of 20 cases. Archives of Ophthalmology. 84(5):572-578. 
Wong V, Au-Yeung Y-CT, Law P-K. 2005. Correlation of functional independence measure for children (weefim) with developmental language tests in children with developmental delay. Journal of child neurology. 20(7):613-616.

Wong V, Wong S, Chan K, Wong W. 2002. Functional independence measure (weefim) for chinese children: Hong kong cohort. Pediatrics. 109(2):e36-e36. 